\title{
Coworking Spaces in the Global South: Local Articulations and Imaginaries
}

Jeremy Tintiangko

Cheryll Ruth Soriano

De La Salle University, Manila, Philippines

Contact details:

Email: jeremytintiangko@gmail.com (corresponding author) cheryll.soriano@dlsu.edu.ph

This is a preprint version of the article accepted for publication in the Journal of Urban Technology published by Taylor and Francis. https://www.tandfonline.com/loi/cjut20

Tintiangko, J. \& Soriano, C.R. (in press). Coworking Spaces in the Global South: Local Articulations and Imaginaries. Journal of Urban Technology.

\begin{abstract}
Building on scholarly explorations on the nuances of labor conditions in emerging knowledge economies in the Global South and the glocalization of the digital labor market, this paper examines how coworking spaces in Philippines are designed and organized. In particular, we explore the role that these alternative workspaces take in addressing the unique needs of local digital platform workers or online freelancers. The Philippines ranks third, after the US and India, among the countries with the greatest number of online freelancers. Drawing from a multisited ethnography of coworking spaces in Metro Manila including interviews with coworking space managers as well as Filipino online freelancers, the paper explores how the latter perceive the role and experience the value of coworking spaces. Echoing Oreglia and Ling's notion of "digital imagination," we find that digital workers sustain a unique sense of "aspirational belonging" to coworking spaces which we describe as a state of willingness to maintain a positive perception of these spaces without any certainty of realizing its promised benefits. We also argue that the very same qualities that render coworking spaces aspirational for online Filipino freelancer function to regulate a degree of in/exclusivity of urban spaces.
\end{abstract}

Keywords: coworking space; digital labor; online freelancing; aspirational belonging; Global South 


\section{Introduction}

The widespread availability of advanced computing technologies, wireless communication devices, and data storage systems have afforded professionals with unprecedented flexibility in terms of where and how they choose to work (Armondi and Di Vita, 2017; Moriset, 2013). In similar fashion, these new technological advancements have enabled more businesses to adopt cost-mitigating strategies such as labor outsourcing and subcontracting (Gerdenitsch et al., 2016; Spinuzzi, 2012). These conditions, coupled with the growing centrality of creative and culture industries to the rapid expansion and growth of digital economies have all, in part, resulted in a "geographic splintering of value chains" and the perceivable increase in the number of "lone eagles" or self-employed professionals and freelancers (Avdikos and Kalogeresis, 2016:2).

Parallel to the rise of the so-called "boundaryless workforce" (Pohler 2012 as qtd. in Gerdenitsch et al., 2016), we have witnessed over the last decade the emergence of a particular form of alternative workplaces known as coworking spaces (Armondi and Di Vita, 2017). Described as "open plan office environments" rented out by various kinds of entrepreneurs and freelancers across all sorts of knowledge industries (Merkel, 2018; Spinuzzi, 2012:399), coworking spaces allow workers to occupy desks and utilize various office services for a fee, alongside other professionals (Akhavan et al., 2018). Beyond its spatial and material qualities, the main draw of coworking spaces lies in its promise to alleviate issues commonly encountered by independent workers such as isolation, low productivity, and the lack of spatial proximity with actors and networks that may facilitate flow of information, resource, and market opportunities (Avdikos and Kalogeresis, 2016; Brown, 2017; Spinuzzi, 2012). Highly regarded as places that provide independent workers with "fluid working environments" (de Peuter et al., 
2017) as well as venues to network and establish social connections (Merkel, 2018), coworking spaces have expanded exponentially over the last decade. From a mere 14 coworking spaces initially reported in 2007 , the number of coworking spaces around the world has risen to 14,411 in 2017 (Hobson, 2019). Meanwhile, the total of coworking space members globally went up to 1.27 million in 2018 from 2016's 890,000 (Global Coworking Survey). Though originating from the Global North, coworking spaces in Asia Pacific have begun to burgeon as well (Merkel, 2015). As of 2017, close to 4,000 coworking spaces reportedly operate across this region (Global Coworking Unconference Conference, 2017). In the Philippines, the site of the study, there are currently over 180 coworking spaces and over 120 of which are located in Metro Manila (Coworker, 2019).

Appearing to substantiate the "celebratory framework" that largely characterizes how coworking spaces are perceived in the mainstream (Gandini, 2015:193), scholarly research have explored the capacity of these spaces to stimulate innovations from the ground up (Wang and Loo, 2017), impact urban environments (Armondi and Di Vita, 2017; Mariotti et al., 2017), foster serendipitous and productive encounters among independent professionals and entrepreneurs (Moriset, 2013), and serve as sites for support for independent workers through the facilitation of knowledge transfer, collaborative problem solving, and companionship (Mariotti et al., 2017; Gerdenitsch et al., 2015; Spinuzzi, 2012; Waters-Lynch and Potts, 2017). Some researchers have also begun to assess the potential of coworking spaces to cultivate "progressive forms of work relations and collective political action" (Merkel, 2018:15; de Peuter et al., 2017). In the midst of the growing "flexibilisation, casualisation, and political deregulation of employment relationships" (Merkel, p.4, 2018), coworking spaces seem to provide disembedded 
workers a means to "reterritorialize the physical organizational structure" that they had lost (Gandini, 2015:198; Wood et al., 2016).

However, scholars have likewise cautioned against the tendency to aggrandize coworking spaces and overlook the tensions that underpin its existence (Moriset, 2013). Moreover, the extent in which these spaces live up to the needs of precarious workers across diversified geographic, economic, and socio-cultural conditions remain in question due to the paucity of research contexts beyond the global center (de Peuter et al., 2017; Gandini, 2015; Merkel, 2018). In this regard, this study seeks to contribute to the "emerging strand of critical coworking research" that considers coworking spaces as inextricably intertwined with issues concerning the increasingly precarious nature of contemporary knowledge work (de Peuter, 2017:2; Merkel, 2018; Avdikos and Kalogeresis, 2016). As part of a broader study on digital labor in the Philippines, this research also dovetails with scholarly explorations on the nuances of labor conditions in emerging knowledge economies in the Global South. The term Global South is used here to refer to a solidary yet non-geographic and deterritorialized conceptualization of nations that are negatively impacted by "contemporary capitalist globalization" and therefore represent "an internal periphery and subaltern position" towards wealthier and subjugating nations which are in contrast, referred to as the Global North (Mahler, 2017).

Guided by this research context, this study explores the roles and functions that coworking spaces in the Philippines assume in relation to the work-related issues faced by Filipino online freelancers. Currently, the Philippines ranks third, after the US and India, among the countries with the greatest number of freelancers and 1.5 million of these workers are digital platform workers or online freelancers engaged in various project-based services or "gigs" (i.e. ranging from software development to more commonly, administrative support, customer 
service, digital marketing, data entry, and language instruction, among others) for overseas clients (Ofreneo, 2018; Schnable, 2018). The decision to focus on this specific worker population is motivated by the fact that this subset of independent knowledge workers make up the majority of freelancers in the Global South and are considered vulnerable and marginalized (see Graham et al., 2017; Wood et al., 2016, 2018; Lehdonvirta, 2016). With this we ask, how are coworking spaces in the Philippines designed and organized? What role do these coworking spaces take in addressing the unique needs of local online freelancers? How do online freelancers perceive the role and value of coworking spaces in their working experiences? To address these questions, this study draws from references produced by the coworking sector (coworking space websites, web articles, social media sites of coworking spaces); semi-structured interviews with managers, proprietors, and receptionists of coworking spaces as well as online freelancers; a focus group interview with online freelancers; informal surveys in closed Facebook groups that cater to the local online freelancing community; as well as a series of multi-sited ethnographic field work in coworking spaces in Metro Manila.

In the following section, we shall provide a brief overview of the history of coworking spaces which will be followed by a review of the ongoing discussion about coworking spaces as spaces where atomized knowledge workers may anchor on for support. From here, we identify the existing gap in the literature in which the study seeks to address. The methodology employed in the study will be detailed as follows, along with the presentation of the findings, analysis, and conclusion. 


\section{From grassroot collectives to global network hubs}

Coworking spaces are venues that lease working spaces (a private office or shared desk) on flexible terms. The fee to work in these spaces typically includes other resources such as unlimited coffee/water/tea, free WiFi internet, common areas, conference/meeting rooms and IT facilities, as well as license to use the coworking space's address, mailbox, and telecommunication lines (Spinuzzi, 2012; Advikos and Kalogeresis, 2016). Looking back, the history of coworking spaces reveals its roots in disruptive economic practices such as the "open source movement" or the "collaborative economy" defined by peer-to-peer sharing (Brown, 2017:113). These days, coworking spaces have moved beyond its communitarian values and grassroots philosophies with the emergence of for-profit, professionally-managed, and global multi-site ventures (Waters-Lynch and Potts, 2016; Capdevila, 2013). Some governments have even begun to instrumentalize coworking spaces as innovation incubators for tech start-ups as detailed in a recent study of coworking spaces in Shanghai (Wang and Loo, 2017). With the growing diversification of the coworking space model, there now exists multiple iterations of the space. They are differentiated in terms of the values espoused by the founders, industry or occupational focus, types of services offered, and membership options in which coworkers may choose to pay per hour/day/month/year (Brown, 2017).

Though often conflated with other alternative places for work, scholars invested in the study of coworking spaces contend that what differentiates coworking spaces from other shared workspaces is its "social and collaborative dimension" (Merkel, 2015, Brown, 2017:114). Despite catering to diverse independent workers which may include micro-businesses, start-up companies, and independent knowledge workers and freelancers, they argue that the central function of coworking spaces is to provide the "physical and relational intermediation to 
networking activities" (Mariotti et al., p.4, 2017) that independent workers need to bolster their social and economic situation, no matter how temporary or fleeting (Gandini, 2015; Spinuzzi, 2012). As Capdevila (2013) has noted, to reduce coworking spaces as mere "open-plan office environments" where strangers merely work alongside one another indefinitely (Spinuzzi, 2012, p.399) is to neglect the fundamental feature of such work places.

\section{Coworking spaces: supportive communities for collaboration, knowledge exchange and socialization?}

Cut off from any form of stable organizational support, independent knowledge workers not only suffer from loneliness and isolation but are also vulnerable to "multiple economic insecurities" (see Wood, et.al, 2016; Merkel, 2018:4). This is why despite the plurality of perspectives from which coworking space are explored, these spaces are primarily examined as a panacea for the precarious work conditions faced by independent knowledge workers. Drawing from the idea of "accelerating serendipity by coworking" (Messina, 2007), Moriset introduced the concept of "serendipity production" as the core principle of coworking spaces in that it increases one's chances of fruitful business encounters (2013:1-2,8). Through its social, spatial, and material elements, coworking spaces have been observed to function as social economies that facilitate information coordination amongst workers through "focal points of mutual expectations" (Graham et al., 152; Waters-Lynch and Potts, 2016; Wang and Loo 2017) and “serendipitous encounters" (Jakonen et al., 2017); as spaces that foster "synergetic relationships" (Capdevila, 2013:6, 11); and even as sites for social and emotional support (Gerdenitsch et al., 2016). Some studies even claim that simply being in the company of others may already provide a form of comfort for coworkers (Gerdenitsch 2016), so much so that "working alone together" 
without necessarily having to socialize or network amongst one another is already more than enough for some workers to carry out productive work (Spinuzzi, 2012:412).

\section{The myth of serendipity production and collaborative communities}

Despite the optimism surrounding coworking spaces, some scholars have challenged the predominantly uncritical framing of these spaces (see Avdikos and Kalogeresis, 2016; Brown, 2017; de Peuter et al., 2017; Gandini, 2015; Hong, 2017; Mariotti et al., 2017; Merkel, 2018; Roderick, 2016). As argued by their studies, the notion of coworking spaces as sites for serendipity production becomes questionable in light of evidence that encounters do not always happen organically nor are spontaneous interactions a common feature of coworking (Akhavan et al., 2018; Brown, 2017; Mariotti et al., 2017). Researchers have attributed this to the fact that coworking spaces attract a heady mix of strangers with varying levels of commitment, working attitudes, and experiences which may render interactions superficial, fleeting, and impermanent (Grugulis and Stoyanova, 2011).

Upon recognizing that geographical proximity may be insufficient in fostering sustainable and productive interactions (Advikos and Kalogeresis, 2016), a number of researchers have since highlighted the importance of spatio-temporal events and materialities (Fabbri, 2016), mindful curation and spatial design (Capdevila, 2013; Avdikos and Kalogeresis,

2016; Brown, 2017), "tools of engagement" such as "web-boards", “social media" platforms, and “physical notice-boards” (Capdevila, 2013; Brown, 2017:116; Waters-Lynch and Potts, 2016; Gerdenitsch et al., 2016), and the facilitating presence of coworking hosts, managers, and team leaders (Merkel, 2015; Spinuzzi, 2012; Brown, 2017) in actively constructing "affective environments designed to facilitate career mobility and professional success" (Gregg and Lodato, 
2018:192).

On the contrary, some coworking spaces have also been observed to do away with the values that once defined these spaces. Instead of upholding the values of "community, collaboration, openness, diversity, and sustainability" (Merkel, 2015:124), the coworking spaces explored by Spinuzzi et al. (2019) in the US, Italy, and Serbia were predominantly driven by the logic of the market - demonstrating little regard to foster collaboration among their workers. Though not completely absent, collaborative communities are not always prioritized nor nurtured by coworking space proprietors and are therefore deemed emergent rather than the dominant standard in these spaces.

\section{Alternative coworking space realities}

In assessing the association between coworking spaces and the plight of independent knowledge workers, it is also necessary to look beyond the "rhetoric of openness and cooperation" (Mariotti et al., 2017:5) to explore other milieus in which coworking spaces may be embedded. Instead of viewing coworking spaces simply as sites of innovation or a novel approach to working, some researchers argue that the emergence of such spaces underplays the increasing normalization of labour informality and flexibility in neoliberal societies (de Peuter et al., 2017; Merkel, 2018). In the midst of "rising unemployment rates" and the "decreasing availability and desirability of firm-based careers", knowledge workers are forced to become lone eagles and seek asylum in coworking spaces (Moriset, 2013; Gandini, 2015:202). De Peuter et al. (2017) points out how coworking spaces simply become a means for companies to offload the costs of maintaining a fresh and dispensable labour supply at the expense of the workers themselves. In its current predominant form, they argue: 
"A commodified service, coworking invites disembedded workers to buy back access to the resources, including workplace community, from which they have been dispossessed" (de Peuter et al., 2017:5).

Apart from highlighting the analogy between coworking spaces and the problematic conditions of contemporary knowledge work, there also exists a growing concern about the tendency of coworking spaces to be mere enclaves for elite, high-skilled workers which may in turn deepen “class and racial divides" (Mariotti et al., 2017; Brown, 2017:116; Gandini, 2015).

In the midst of all these debates, a perceivable void in the current discussion of coworking spaces is the extent in which these places are inclusive of different types of precarious workers. Although researchers have identified the following recurring actors of coworking spaces: self-employed creatives, start-up or small-medium business owners and employees, professional consultants, freelancers, and contractors who work with clients overseas (Spinuzzi 2012; Moriset, 2013; Brown 2017; Gerdenitsch et al., 2016), little is uncovered about how the differing backgrounds of workers shape their imaginary of coworking spaces (de Peuter et al., 2017). From this perspective, it seems inevitable to wonder how the narrative of workers, who may not be able to afford the advantages and benefits of coworking spaces, fit in the current rendering of the global coworking space imaginary.

Literature on contemporary labor points to a largely overlooked segment of the freelance and digital labor force which has proliferated in direct relation to the rapidly growing digital industries. Collectively defined as digital platform workers, workers in the gig economy, or simply digital workers or online freelancers, this subcategory of precarious workers who are largely situated in the Global South have a significantly lesser mobility and command of territory than their counterparts in the Global North; mainly relying on online labor platforms and 
microwork intermediaries such as Upwork (formed from a merger of Odesk and Elance in 2015), GoLance, or Onlinejobs.ph to obtain and carry out a variety of virtual jobs for clients who are often based in more affluent countries such as the US, Canada, and the UK (Graham et al.,2017; Wood et al., 2016). Yet despite the hopefulness surrounding this fast-growing labor market, the literature on digital labor specifically online platform labor in the Global South has been widely critical; where "microworkers" are understood to collectively perform the role of a "standing reserve" for unwanted jobs in high-technology workplaces (Irani, 2013:18).

Revealing the variegated realities of the digital labor in the Global South, researchers have explored the issues faced by these workers such as isolation, inability to connect to a supportive "community" (Gandini, 2015:198; Graham et al., 2017), arbitrary labor practices by foreign employers (Lehdonvirta, 2016), new forms of worker alienation and exploitation (Irani, 2013; Casili, 2017), and the colonization of personal space which Melissa Gregg has defined as "presence bleed" (2013:23-125, 131). Partly, what some of these conditions present is a crisis of territorialization defined by the diminishing boundaries of spatial and temporal limits. Given these scenarios, it does not seem improbable to view the emergence of coworking spaces as a promising phenomenon for these precarious workers.

In this regard, this study seeks to contribute to the ongoing discourse on coworking spaces by examining the role that coworking spaces play in relation to the work-related experiences of Filipino digital platform workers, herein referred to as online Filipino freelancers. Despite the fact that coworking spaces continue to be examined in various perspectives which have shed light on its labor mitigating potentials, little attention has been paid to the extent in which these spaces can offer the same benefits for precarious online workers situated in sociocultural and geographic settings that differ from those commonly explored in the current 
literature. In understanding how online freelancers imagine and experience these spaces, what is foregrounded is the fact that coworking spaces, like any other space, is socially and politically constructed (Lefebvre, 2009). Therefore, we are approaching this research from a perspective that acknowledges that the meanings and concepts ascribed to coworking spaces are not fixed and rather, contingent on the confluence of elements that are in constant struggle and negotiation with one another. In adopting this perspective and approaching the coworking space topic with a distinct focus on its relationship with online freelancers in the Philippines, it allows us not only to understand the extent in which coworking spaces are able to address the needs of independent knowledge workers who are mired in a distinct set of work-related issues but also to reassess the dominant narratives perpetuated about coworking spaces.

\section{Methods, sites, and study participants}

This study draws from 20 semi-structured interviews with managers, proprietors, and receptionists of coworking spaces as well as online Filipino freelancers. Some of the respondents were met at the coworking spaces while the rest of the respondents were either referred through personal contacts or obtained through snowball sampling (Hesse-Biber, 2017) with online Filipino freelancers that the researchers have engaged with in the public and closed Facebook groups of online Filipino freelancers. The respondents were also invited to participate in a focus group interview in March 2018 to discuss the nature of their working space, what qualities they require of workspaces, and their use of coworking spaces.

The study also benefited from a series of multi-sited ethnographic field work in 10 coworking spaces in Metro Manila. The interviews were mostly carried out on site or were done over video communication software, Zoom. We visited coworking spaces located in diverse parts 
of the metropolis (i.e. Makati, Taguig, Quezon and Pasig cities) - from the central to the outskirts - for the opportunity to come across coworkers from different socio-economic backgrounds as well as to find out how diverse coworking spaces can be depending on the location. As part of a broader study on digital labor in the Philippines, the study also drew from a digital ethnography of online freelance workers' online communities conducted from November 2016 to December 2017. Within public and closed Facebook groups dedicated to the online Filipino freelancing community, several encounters transpired between the researchers and the online Filipino freelancers wherein questions were posted about their coworking space habits, inquiries about the coworking spaces that they frequent the most, and also to solicit potential interview respondents. Pseudonyms were used in place of the respondents' real names to protect the privacy.

[Figure 1 right around here]

References including websites, web articles, social media pages and accounts of coworking spaces produced by the coworking sector and the proprietors of the sampled coworking spaces were also consulted to verify and cross-analyze the data gathered during the site visits and interviews. In exhausting a variety of qualitative methods that makes verification, comparison, and contrast possible, we generated a wealth of insights on the "shared practices, meanings, social contexts, and interrelations" of the respondents (Boellstorff et al., 2012:88). After organizing the data from interviews and participant observation, coding methods were used to draw emergent themes and recurring patterns, founded on grounded theory techniques (Charmaz, 2000; Saldaña, 2009:70,159-60).

\section{Online freelancers in the Global South: Coworking space imaginaries and experiences}


Out of the 10 coworking spaces visited, nine (9) expressed a commitment to foster community, innovation, and growth for entrepreneurs, freelancers, start-ups, and creative professionals as evidenced by their branding collaterals, knowledge transfer activities (i.e. workshops, seminars), management-led social events, and the presence of coworking space managers, community managers, and team leaders who serve the role of facilitators. (See Table 1 for a detailed background on the sampled coworking spaces.) [Table 1 right around here]

Appearing to have combined different elements of other alternative spaces for work (such as makerspaces or business incubators) with the core features of coworking, the coworking spaces visited provide evidence of their growing diversification (Brown, 2017; Moriset, 2013; Waters-Lynch and Potts, 2016). For example, Roots Katipunan and Diligence Café brand themselves as coworking spaces, however, both coworking spaces have also dedicated an area of their spaces to serve as a retail space that supports local entrepreneurs and social enterprises. There is also The Other Room, a coworking space and a vinyl shop located within a creative district. Stemming from the founders' intention to maximize the space of their vinyl shop and likewise have a productive space to carry out their freelance work, The Other Room is evocative of the organic and communal roots of coworking spaces.

Meanwhile, a model which reflects the growing trend among coworking spaces in the Global North to inhabit abandoned locations, has emerged in the form of First Coworking Community (Mariotti et al., 2017). This coworking space is housed in a heritage district which local creative firms and art collectives are seeking to revive. There also exists a segment of coworking spaces in Metro Manila that strike a balance between home and office. Usually modest in space, coworking spaces like these are often located along the fringes of cities. 
Catering to a more dispersed demographic, these spaces attract coworkers from the immediate neighborhood and bear no stringent coworking cultures. Examples of these coworking spaces are Racket Room Collective and Cofficina Café + Cowork.

On the other hand, Impact Hub, LookUs, Co.Lab, and 47East are coworking spaces that likewise function as business incubators and startup accelerators by offering consultancy services and accelerator programs. Reflective of the highly-commercialized crop of coworking spaces that adhere to the ideals of a global coworking space brand, these spaces are home to start-up companies and elite freelancers with specialized skills and higher-earning capacities, bear more premium services at higher rates (reaching up to P1,000 or US\$20 per day), and locate themselves within affluent and central business districts of Metro Manila.

\section{Aspirational belonging and the promise of coworking spaces}

Whether it was a franchise of a global chain or a more modest coworking space operated by local entrepreneurs, the coworking spaces visited in this study all seek to embody the same coworking space principles as those of its equivalents in the Global North, particularly the concepts of openness, collaboration, accessibility, and community (Moriset, 2013) (See Table 1 for a detailed account of the values espoused by the sampled coworking spaces). This demonstrates the conscious and deliberate attempt to pattern their spatial design and values on global expectations of coworking spaces. However, it is not enough to understand coworking spaces as they are configured by its proprietors but also how these spaces are perceived and experienced by individuals as co-constructors of the space (Spinuzzi, 2012). In acknowledging this perspective, it would have been ideal to obtain the insights and meanings generated by Filipino online freelancers who cowork in the sampled coworking spaces. However, site visits revealed that online Filipino freelancers were notably absent in these spaces. 
As remarked by a manager at Co.Lab, "In our 5 years of existence, they've [freelancers] not been a major demographic that we've catered to" (G. Perez, personal communication, August 1, 2017). Informal interviews with other coworking space employees also supported this palpable absence by reporting, based on records, that online Filipino freelancers hardly visited and availed of their services. When asked about their level of engagement with the online freelancing sector, one of the managers of Roots Katipunan stated that they had no intention of making active efforts to engage the online freelancing sector as they are not the target market.

It comes as no surprise then that online freelancers interviewed felt that they are not the primary demographic of these spaces. As stated by Misa, a female freelance social media strategist who also acts as a Facebook moderator for a group that caters to the online Filipino freelancing community, "I really don't think that we [online freelancers] are the target. Because if we are, you'd immediately meet people like you there. But that has never been the case during the few times that I've visited nor is it the norm according my peers. In fact, I only know of one online freelancer who coworks and that's probably because he earns a lot.” (M. Santos, video conference call, August 16, 2017). Indeed, even one of the coworking space managers interviewed in the study admitted that they only make use of the term freelancers as a catch-all term for anyone who has a flexible work schedule (A. Villa, personal communication, July 28, 2017).

Seeing coworking spaces as alternative yet ideal places for work, the respondents often resorted to assuming the perspective of high-earning or elite freelancers, entrepreneurs, and owners of start-up companies when conjuring their imaginaries about the nature of coworking spaces. Reflected in their constant use of phrases such as "If I were a startupper or an entrepreneur....", "If I were earning this much money...", "If I were to imagine myself as...", the 
respondents appeared to be merely projecting the potential benefits of coworking spaces instead of something that they can personally experience. This perceivable condition internalized by online freelancers seem to echo Elisa Oreglia and Rich Ling's notion of "digital imagination". Applied in the context of digital technology use among non-techno-elites in the Global South, digital imagination is described as "the process by which individuals within a society develop an understanding of the potentials, the limitations, and eventually the threats of digital technology" (2018:571). Like Oreglia and Ling's non-techno-elites who grapple with the promise of these new technologies, online freelancers similarly conduct a "mental matching" to envision the potentials of coworking spaces in contrast to their context-specific needs (2018:571).

This leads us to argue that the online Filipino freelancers in this study have come to adopt a state of mind wherein they are merely sustaining a positive vision of coworking spaces based on its global vision/image despite not actually benefitting from its promises just yet. Drawing from the notion of the context-specific ways in which individuals utilize imagination and draw from their own socio-cultural positions as a way to make sense of the world, despite having only a limited set of tools and knowledge (Oreglia and Ling, 2018), we refer to the state of mind being internalized by online freelancers with regard to coworking spaces as "aspirational belonging". In tracing the reasons behind online freelancer's inability to fully experience and exercise their belongingness in such spaces, we have identified two intermingling barriers based on the experiences and concerns raised by the respondents.

\section{Spatial design and configuration of local coworking spaces}

Owing to its history as grassroots solutions to the increasing displacement and isolation experienced by independent workers, coworking spaces are generally considered as accommodating and welcoming spaces. And yet, coworking spaces, when re-evaluated in the 
context of the Global South, appear to be the exact opposite. In particular, we have identified the spatial design and configuration of coworking spaces - which refer to operational qualities of coworking spaces such as location, rates, aesthetic design, as well as preferred actors and communities - as the precise elements that determine the varying degrees of in/exclusivity that these spaces offer for online Filipino freelancers.

Whereas coworking spaces in the Global North proved geographically accessible for independent workers, respondents expressed the struggle to find easily accessible coworking spaces. This is due to the fact that despite being located within close proximity to universities, entertainment districts, and occasionally, densely populated neighborhoods, the increasingly worsening traffic conditions render the travelling experience to and from these spaces severely inconvenient. As narrated by Clara, a female virtual assistant, there was an instance when she just gave up on her plan to visit a coworking space upon realizing halfway through travelling that commuting to the location would be impractical and exhausting (C. De Guzman, personal communication, July 13, 2017).

Another factor seen to contribute to the alienation experienced by online freelancers are the very actors and communities that populate such spaces. Based on our visits to coworking spaces, these spaces appear to be more commonly inhabited by digital entrepreneurs of start-up companies; highly skilled knowledge workers such as freelance lawyers, consultants, and architects; as well as foreign digital nomads who often form a community amongst themselves, which are occupations and work cultures that starkly contrast with the roles that online Filipino freelancers often assume as previously mentioned. This observation seems to be related with the fact that these elite class of workers really are the primary target market of their spaces. This information has been disclosed by several managers of coworking spaces, particularly those that 
are part of a global franchise. Without being explicitly told, the online freelancers knew, based alone on the fact that it was difficult to come across fellow online freelancers in coworking spaces, that these spaces could go on without them. Furthermore, the respondents also noted the asymmetry between what the coworking spaces are branding themselves as and the actual experience of coworking in Manila. Clara, for example, shared how her coworking space experiences fell short of her expectations in that the spaces offered little chance for socialization and networking. Her initial experience was confirmed when she asked a fellow freelancer about whether or not that was really the case: "Even in one of those more expensive coworking spaces in Makati, my friend told me that it's just really quiet. You're all seated beside each other, you work, but it's just quiet", she narrated (C. De Guzman, personal communication, July 13, 2017). While some of the proprietors interviewed expressed no interest in accommodating the growing community of online freelancers, there are those who simply lacked the motivation and know-how to engage this subset of digital workers. Although the coworking spaces are designed to "invite chats over coffee" (G. Perez, personal communication, August 1, 2017) there is little proof that these encounters have led to business opportunities or collaborations let alone for online freelancers, who are to begin with, already absent in these spaces or relegated to a marginal position when they do decide to avail of these spaces. Whereas the literature stresses the need for coworking spaces to utilize "tools of engagement" as well as assign managers who must take on the role of "relationship-builder, mentor and knowledge provider" (Brown, 2017:116, 121), some of the sampled coworking spaces merely appeared to function as rentable spaces for work despite claiming to espouse the tenets of coworking spaces as observed in their social media pages and websites. Others even had receptionists in place of coworking space 
managers and team leaders on site. Even more so, the respondents cited the lack of managementled workshops or events that cater directly to online freelancers.

In her many years of being an active member of online freelancing communities, Misa claims that she has never encountered any partnerships between coworking spaces and the online freelancing community (M. Santos, video conference call, August 16, 2017). Meanwhile, Cher also commented about the lack of initiative on the part of coworking spaces to get to know their clientele deeper. She claimed, "If collaboration and community are really what they are after, then obtaining the coworker's occupational profile must be a standard. This way, they can easily link up people who might benefit from having this particular connection" (C. Mariposque, video conference call, August 16, 2017). Given the lack of mindful curation in most of the coworking spaces we visited, the respondents fail to realize the potentials of these coworking spaces to "precipitate coworker knowledge sharing" or serve as a "marketplace" for workers to showcase, network, or promote their services to external parties (Brown, 2017:116).

Yet perhaps one of the most consequential factors that discourage Filipino online freelancers from going to coworking spaces is the issue of cost. While coworking spaces in more affluent countries serve as a means to ease the cost of independent work (Avdikos and Kalogeresis, 2016; Waters-Lynch and Potts, 2016), the average rate of P550 (around US\$10) per day, which is higher than the average minimum wage in Metro Manila, proves too costly for Filipino online freelancers to expend on the regular. Others also pointed out that going to a coworking space also entails other costs such as spending money for meals and commuting. "What I shell out in a coworking space just for one day is already 1/3 of my monthly bill for the Internet," Cher explained (C. Mariposque, video conference call, August 16, 2017). 
Given this reality, the rate of coworking spaces can be considered as a fundamental barrier between online Filipino freelancers and coworking spaces in that it wholly affects their decision to cowork. As pointed out by a high-profile online freelancer, and community leader who coaches hundreds of freelancers in multiple training courses, "As long as there are cheaper alternatives to coworking spaces, it will be hard for coworking spaces to takeoff for freelancers because not all of them earn well' (J. Danoy, personal communication, July 2017). For workers who still do not earn well and are unable to subscribe to fast and reliable internet connection at home, or during power outages, there are several available options for connectivity such as coffee shops with free or paid WiFi or public ICT access spots called "computer shops" or "cybercafés."

However, it is crucial to point out that the rates of coworking spaces are largely commensurate to the coworking spaces' spatial design and operational nature than to economic conditions beyond the control of coworking spaces. The rates offered by coworking spaces correspond to the facilities and amenities offered by the coworking spaces which often include hip, cozy, upscale, and industrial open office set-ups; comfortable seats and optimal working desks; high-speed internet; café facilities; as well as sound-proof and glass-walled meeting rooms. Given the proprietors' desire to maintain the global standards of coworking spaces, keep up with the operational costs of the business, and earn profit, the rates of the coworking spaces will never be considerate of the financial capacities of lower-tiered freelance workers.

By evaluating the spatial design and operational nature of coworking spaces, coworking spaces seem to favor only a limited demographic of digital worker, particularly those who have the financial capacity to afford going to coworking spaces regularly. Furthermore, the same qualities that render coworking spaces aspirational for the online Filipino freelancers are in fact 
serving a regulatory function in terms of who gets to reap the benefits of such spaces and those who cannot.

\section{Differing imaginaries of freelance work}

As earlier argued, coworking spaces in the Global North emerged and thrived with the collapse of traditional work culture as a consequence of the recent economic crisis and as a facilitator of solidarity, resource sharing, and serendipity production among freelancers (Akhavan et al., 2019). Therefore, the coworking space, alongside the freelancing model, is perceived as an ideal arrangement to minimize the precarity yielded by such economic condition. On the other hand, for Filipino workers in the Philippines where informality and precarity of labor is the norm (Ofreneo, 2013; Soriano and Cabanes, forthcoming), the flexibility that freelancing, as well as working from home allows in terms of having the option to work in nontraditional settings, has been promoted and also perceived by online freelancers, as an attractive, liberating and unprecedented mark of progress. In fact, for local knowledge workers, this flexibility and possibility of "working from home" remains to be its foremost selling point. From hands-on parents struggling to fulfill their nine to five office jobs while caring for their children and average employees who are incurring substantial financial losses from the increasingly worsening traffic conditions in the metropolis to skilled professionals who cannot find jobs that offer decent work-life balance, working from home or elsewhere as a digital worker has proven to be an ideal option. This then implies a tension rooted in an imaginary espoused by the local coworking spaces, which take after the coworking space imaginary perpetuated in the Global North, vis a vis the freelancing culture espoused by online Filipino freelance workers.

As Nicolo remarked, "I have a quiet house, no one bothers me, I have really good Internet. I honestly don't have a reason to go to a coworking space," (N. Canlas, video call, 
August 15, 2017). Nicolo's stance on coworking spaces was corroborated by a female freelance worker during our focus group discussion. Another male freelance worker also explained, “ $I$ explicitly pursued online freelancing because I did not want to interact. If one would go to a coworking space only for the Internet, then why not just go to a computer shop where it is cheaper?" (B. Payumo, personal communication, March 20, 2018). Apart from the availability of a work-conducive environment at home and efficient technologies for work, the respondents also claim that there are perks to working from home which they really enjoy, such as caring for the family while working, and which ultimately convinced them to leave their fulltime physical jobs. As shared by a couple who both work as online freelancers during the focus group interview, working from home "allows them to be hands-on parents" (C. Enriquez and P. Saw, personal communication, March 20, 2018).

Without factoring the issue of cost, the workers also claim that there is a certain comfort in being able to work from home. As remarked by Cher, "I really prefer working from home because you don't have to worry about how you present yourself!' (C. Mariposque, video conference call, August 16, 2017). This sentiment was echoed by another freelancer who even went so far as to question the point of coworking spaces in the local context. In her words, "I do not get the point of coworking spaces because the point of freelance work is to work from home, where I don't have to dress up nor do my make-up!' (C. Enriquez, personal communication, March 20, 2018).

In contrast to independent workers in the Global North who lamented the collapsing boundaries between work and personal spaces as well as the isolation that often comes with working from home, the online Filipino freelancers seem to embrace and even prefer the fluid work culture that online freelancing enabled them to enjoy. Filipino freelancers are particularly 
drawn to digital freelance work in order to fulfill domestic roles while remaining economically productive. Complicated by worsening traffic conditions in the metropolis that impede movement and extend traditional commuting hours, Filipino freelance workers also perceive work-at-home arrangements as an important respite from having to travel to work and spend time more productively. Deriving from these observations, it appears that the dominant coworking space model as transported from the Global North does not suit the freelance work culture imbibed by the digital workers involved in the study.

\section{Reflections and Conclusion}

In the Global North, coworking spaces emerged at a time when traditional standards of employment have begun to erode (de Peuter et al., 2017). Amid all its contradictions, coworking spaces may function as fertile sites that empower independent knowledge workers in more ways than one. As demonstrated by coworking space scholars, coworking spaces can effectively host a variety of independent knowledge workers who seek to appease isolation and establish connections that may prove economically and socially beneficial (Akhavan et al., 2019). Given these observations, it is not hard to imagine why the dominant outlook towards these alternative workspaces has been widely optimistic. Unfortunately, in economically challenged countries such as the Philippines, where crisis and precarity are the norm for the majority, it is quite challenging to imagine coworking spaces as empowering sites that alleviate isolation and loneliness or as spaces that hold exponential economic opportunities for the average independent digital worker such as the online Filipino freelancers in the study. From its spatial design and configurations to the work culture that these spaces promote, which mutually result in a coworking space imaginary that ascribes to the dominant coworking space model in the Global 
North, local coworking spaces in the Philippines manage to appear as venues where the freelancers may potentially realize their "belongingness" in the global network of the digital economy.

Ascribing to this idealized notion of coworking spaces, as perpetuated further in the mainstream media and likewise in their respective professional and personal networks, the respondents actively and readily imagine their place within it and how they can benefit from the advantages offered by these spaces. However, upon examining the significance and purpose that these spaces assume in their lives, coworking spaces fell short of the online Filipino freelancers' needs and expectations. Ironically a result of the precise inclination of local coworking spaces to uphold the global standard along with the fact that the workers are rooted in a distinct set of socio-economic and geographic realities that the global iterations of coworking spaces were not designed to address, online platform workers are left in a perpetual state of aspirational belongingness when it comes to these spaces.

Evidently, the non-critical disposition associated with coworking spaces seem to have ignored the reality of how socio-economic and geographic inequalities affect the way certain groups of people experience and perceive spaces or are excluded from it entirely (Gandini, 2015:202; Brown, 2017:121). As Gandini has speculated early on, coworking spaces indeed reiterate the "illusory enthusiasm", inequalities, and shortcomings that characterize the "creative class" imaginary $(2015: 194)$. As it is transported to the Global South without much attempt by the proprietors to adjust or appropriate its services to address the unique needs and concerns of a diverse community of independent knowledge workers, coworking spaces in the Philippines fail to live up to its promises. It is also crucial to note that since the coworking spaces sampled in the study only caters to high-earning freelancers, entrepreneurs, and digital nomads, coworking 
spaces in the Global South inevitably sidelines other forms of independent knowledge workers and imposes a delineation between the "upwardly mobile worker" vis-à-vis workers who are bound by economic and socio-cultural constraints (Hong, 2017: 554). In this regard, it would be compelling to know how coworking spaces would fare when assessed in the perspective of marginalized gig economy workers in the Global North and in other parts of the Global South. Meanwhile, it may also be fruitful to consider other spaces where digital workers have been found to coalesce such as virtual communities, as potential sites for community, collaboration, and collective action (Lehdonvirta, 2016; Wood et al., 2018).

Currently, coworking spaces in the Philippines challenge the dominant narratives that have come to form around it; particularly, as labor mitigating sites for online freelance workers in the gig economy. With this, we contend that the relationship between Filipino digital workers and coworking spaces mirror the asymmetries of the digital labor landscape in that in some ways, digital labor is promising and aspirational for many workers and yet, at the same time, bears the tendency to reinstate divisions between workers and produce asymmetries. This is due to the fact that coworking spaces in the Global South tend to favor only a select class of independent knowledge workers while largely ignoring the needs of disembedded workers who are more vulnerable to the perils of precarious labor. In many ways, this exploration of coworking spaces expands not only our understanding of the nature of contemporary urban spaces but also of labor.

\section{References}

V. Avdikos and A. Kalogeresis, "Socio-Economic Profile and Working Conditions of Freelancers in Co-Working Spaces and Work Collectives: Evidence From the Design Sector in Greece," Area,1:8 (2016)<doi:10.1111/area.12279> Accessed July 11, 2017.

T. Boellstorff, B. Nardi, C. Pearce, T.L. Taylor, Ethnography and virtual worlds a handbook of method (New Jersey: Princeton University Press, 2012).

J. Brown, "Curating the "Third Place"? Coworking and the Mediation of Creativity," 
Geoforum, 82 (2017) <doi:10.1016/j.geoforum.2017.04.006> Accessed July 122017.

I. Capdevila, "Knowledge Dynamics in Localized Communities: Coworking Spaces as Microclusters," SSRN Electronic Journal (2013) http://ssrn.com/abstract=2414121 or $<$ https://doi.org/10.2139/ssrn.2414121> Accessed July 11, 2017.

C. Charmaz, "Grounded Theory: Objectivist and Constructivist Methods," in N.K. Denzin and Y.S. Lincoln, S., Handbook of Qualitative Research (Thousand Oaks, California: Sage, 2000) 509-535.

Coworker, <https://www.coworker.com/philippines> Accessed March 15, 2019.

G. de Peuter, N. Cohen, and F. Saraco, "The ambivalence of coworking: On the politics of an emerging work practice," European Journal of Cultural Studies 20:6 (2017) < https://doi.org/10.1177/1367549417732997> Accessed March 14, 2019.

J. Fabbri, "Unplugged - "Place as Spatio-Temporal Events": Empirical Evidence from Everyday Life in a Coworking Space," Management 19:4 (2016) <https://www.cairn.info/revuemanagement-2016-4-page-353.htm\#> Accessed July 29, 2017.

E. Ferraz, "The state of freelancing in the PH," Rappler (June 27, 2017) $<$ https://www.rappler.com/business/features/97609-state-freelancing-philippines-upworkplatform $>$ Accessed October 15, 2017.

A. Gandini, “The Rise of Coworking Spaces: A Literature Review," Ephemera, 15:1 (2015) 193205.

C. Gerdenitsch, T.E. Scheel, J. Andorfer, C. Korunka, “Coworking Spaces: A Source of Social Support for Independent Professionals," Frontiers in Psychology, 7 (2016) $<$ doi:10.3389/fpsyg.2016.00581> Accessed July 10, 2017.

Global Coworking Survey, <http://www.deskmag.com/en/background-of-the-2018-globalcoworking-survey-market-research $>$ Accessed March 15, 2019. Global Coworking Unconference Conference, <https://gcuc.co/wp-content/uploads/2017/12/GCUC-GlobalCoworking-Stats-2017-2022.pdf $>$ Accessed March 15, 2019.

M. Graham, I. Hjorth, V. Lehdonvirta, "Digital Labour and Development: Impacts of Global Digital Labour Platforms and the Gig Economy on Worker Livelihoods," Transfer: European Review of Labour and Research, 23:2, (2017) <https://doi.org/10.1177/1024258916687250> Accessed August 4, 2017.

M. Gregg and T. Lodato, "Managing Community: Coworking, Hospitality and the Future of Work," in B. Röttger-Rössler and J. Slaby, ed.1, Affect in Relation Families, Places (New York, NY: Routledge, 2018) 175-196.

M. Gregg, "Presence Bleed: Performing Professionalism Online" in M. Banks \& R. Gill, Theorizing Cultural Work: Labour, Continuity and Change in the Cultural and Creative Industries (New York: Routledge, 2013) 122-134.

I. Grugulis and G. Stoyanova, "The Missing Middle: Communities of Practice in a Freelance Labour Market," Work, Employment, and Society 25:2 (2011) 342-351.

S. Hesse-Biber, The Practice of Qualitative Research (Thousand Oaks, California: Sage 2017).

K. Hobson, "The Global Coworking Growth Study," Coworking Resources, (May, 15, 2019) < https://www.coworkingresources.org/blog/key-figures-coworking-growth> Accessed August 31, 2019.

R. Hong, "Office Interiors and the Fantasy of Information Work," Triple C 15:2 (2017) $<$ https://doi.org/10.31269/triplec.v15i2.763> Accessed July 12, 2017.

L. Irani, "The Cultural Work of Microwork," New Media \& Society 17:5 (2013)< doi:10.1177/1461444813511926> Accessed May 7, 2017. 
M. Jakonen, N. Kivinen, P. Salovaara, and P. Hirkman, "Towards an Economy of Encounters? A critical study of affectual assemblages in coworking," Scandinavian Journal of Management, 33:4 (2017) < doi:10.1016/j.scaman.2017.10.003> Accessed December 3, 2017.

H. Lefebvre, "Space" in N. Brenner and S. Elden, ed.1, State, Space, World: Selected Essays (Minneapolis, MN: University of Minnesota Press, 200) 185 - 195.

V. Lehdonvirta, "Algorithms that Divide and Unite: Delocalisation, Identity and Collective Action in 'Microwork'," in J. Flecker, ed.1, Space, Place and Global Digital Work, Dynamics of Virtual Work, (UK: Palgrave MacMillan, 2016) 53-80 < doi 10.1057/978-1-137-480873_4> Accessed May 31, 2017.

A. G. Mahler, "Global South," in E. O' Brien, Oxford Bibliographies Online in Literary and Critical Theory (UK: Oxford University Press, 2017) < doi: 10.1093/OBO/97801902219110055> Accessed March 15, 2019.

I. Mariotti, C. Pacchi, and S.D. Vita, "Co-working Spaces in Milan: Location Patterns and Urban Effects," Journal of Urban Technology 24:3 (2017) < doi:10.1080/10630732.2017.1311556> Accessed July 29, 2017.

J. Merkel, "Coworking in the City," Ephemera 15:2 (2015) < http://openaccess.city.ac.uk/14478/> Accessed March 14, 2019.

J. Merkel, “'Freelance isn't free.' Co-working as a critical urban practice to cope with informality in creative labour markets," Urban Studies Journal Limited 56:3 (2018) < DOI: 10.1177/0042098018782374> Accessed March 12, 2019.

C. Messina, "Accelerating Serendipity with Coworking," Coworking Community Blog (June 28, $2007<\mathrm{http}$ ://coworking.wordpress.com/2007/06/28/accelerating- serendipity-with coworking $>$ Accessed November 20, 2017.

B. Moriset, "Building New Places of the Creative Economy," paper presented at Geography of Innovation International Conference (Utrecht, January $23-25,2014$ ) <https://halshs.archivesouvertes.fr/halshs-00914075> Accessed July 29, 2017.

R. Ofreneo, "Rise of Freelance Work Force," Business Mirror (August 16, 2018) < https://businessmirror.com.ph/2018/08/16/rise-of-freelance-work-force/> Accessed March 15, 2019.

R. Ofreneo, E. Precarious Philippines: Expanding informal sector, "flexibilizing" labor market. American Behavioral Scientist, 57(4), (2013) 420-443. < doi:10.1177/0002764212466237>

E. Oreglia and Rich Ling, "Popular Digital Imagination: Grass-Root Conceptualization of the Mobile Phone in the Global South," Journal of Communication 68 (2018) $<$ doi:10.1093/joc/jqy013> Accessed June 19, 2018.

I. Roderick, "The Politics of Office Design: Translating Neoliberalism Into Furnishing," Journal of Language and Politics 15(3) (2016) < doi:10.1075/jlp.15.3.03rod > Accessed July 12, 2017.

J. Saldaña, The Coding Manual for Qualitative Researchers (Los Angeles, CA: Sage, 2016).

S. Schmidt, V. Brinks, S. Brinkhoff, "Innovation and Creativity Labs in Berlin," Zeitschrift für Wirtschaftsgeographie 58:4 (2014) <doi 10.1515/zfw.2014.0016> Accessed July 202017.

C. Shnable, "Freelancing Taking Root in the Philippines - study" Rappler (April 1, 2018) < https://www.rappler.com/business/199334-freelancer-market-growing-philippines-paypal> Accessed March 15, 2019.

C. Soriano and JV. Cabanes, "Between 'world class work' and 'proletarianised labor': Digital labor imaginaries in the Global South.” In E. Polson, L. Schofield-Clarke, and R. Gajjala (Eds). Routledge Companion to Media and Class. (London \& New York: Routledge, 2019. 
C. Spinuzzi, "Working Alone, Together: Coworking as Emergent Collaborative Activity," Journal of Business and Technical Communication, 26:4 (2012) $<$ http://journals.sagepub.com/doi/abs/10.1177/1050651912444070> Accessed September 8, 2017.

C. Spinuzzi, Z. Bodrožić, G. Scaratti, S. Ivaldi, "Coworking is about community" but what is "community" in coworking?" Journal of Business and Technical Communication, 33:2 (2019) $<$ https://doi.org/10.1177/1050651918816357> Accessed March 29, 2019.

B. Vidaillet and Youcef Bousalham, "Coworking spaces as places where economic diversity can be articulated: Towards a theory of syntopia" Organization $(2018)<$ https://doi.org/10.1177/1350508418794003> Accessed March 14, 2019.

B. Wang and B. Loo, "Hubs of Internet Entrepreneurs: The Emergence of Coworking Offices in Shanghai, China" Journal of Urban Technology 23:3 (2017) $<$ http://dx.doi.org/10.1080/10630732.2017.1285124> Accessed July 28, 2018.

J. M. Waters-Lynch and J. Potts, "The Social Economy of Coworking Spaces: A Focal Point Model of Coordination," SSRN Electronic Journal,1-23 (2016) < doi:10.2139/ssrn.2770874> Accessed July 29, 2017.

A. J. Wood, M. Graham, V. Lehdonvirta, H. Barnard, and I. Hjorth, "Virtual Production Networks: Fixing Commodification and Disembeddedness" paper presented at The Internet, Policy, and Politics Conferences (Oxford, September 22 - 23, 2016) Accessed March 30, 2017.

A. J. Wood, V. Lehdonvirta, M. Graham, "Workers of the Internet Unite? Online Freelancer Organisation Among Remote Gig Economy Workers in Six Asian and African Countries," New Technology, Work and Employment 33:2, (2018) 95-112.

\section{Disclosure statement}

No potential conflict of interest was reported by the authors.

\section{Appendix}

Table 1: Sampled coworking spaces in the Philippines

\begin{tabular}{|l|l|l|l|}
\hline $\begin{array}{l}\text { Coworking } \\
\text { Space }\end{array}$ & Location & \multicolumn{1}{|c|}{ Description } & \multicolumn{1}{|c|}{ Rental Price } \\
\hline LookUs & $\begin{array}{l}\text { Mandaluyong } \\
\text { City }\end{array}$ & $\begin{array}{l}\text { LookUs offers an open office space, studio } \\
\text { offices and meeting rooms. Aesthetically, } \\
\text { LookUs resembles a hip and industrial open } \\
\text { office design that is popular among coworking } \\
\text { spaces. } \\
\text { LookUs envisions to help digital workers } \\
\text { achieve professional growth by "building a } \\
\text { community of coworkers". In keeping with this } \\
\text { aim, LookUs has held several events such as a } \\
\text { (U) } \\
\text { series of workshops on content writing and a by- } \\
\text { invitation open house event. (As of writing this }\end{array}$ \\
\hline
\end{tabular}




\begin{tabular}{|c|c|c|c|}
\hline & & $\begin{array}{l}\text { paper, LookUs has already ceased its } \\
\text { operations.) }\end{array}$ & \\
\hline 47 East & Quezon City & $\begin{array}{l}47 \text { East reflects characteristics of premium } \\
\text { coworking spaces in the Global North. } 47 \text { East } \\
\text { takes pride in having a pool of investor-members } \\
\text { and consultants that can provide mentorship and } \\
\text { technical assistance to entrepreneurs. Though } \\
\text { smaller than other premium coworking spaces, } \\
47 \text { East bears a sophisticated modern open office } \\
\text { design. }\end{array}$ & $\begin{array}{l}\text { P300/day for } \\
\text { members only } \\
\text { (US\$5.6/day) } \\
\text { P500 (US } \$ 9.5 \text { ) } \\
\text { membership fee }\end{array}$ \\
\hline $\begin{array}{l}\text { Racket Room } \\
\text { Collective }\end{array}$ & Quezon City & $\begin{array}{l}\text { Out of all the coworking spaces visited, Racket } \\
\text { Room Collective was the smallest. With no } \\
\text { private rooms for closed-door meetings, workers } \\
\text { are made to work in close proximity to one } \\
\text { another. Despite this, Racket Room Collective } \\
\text { manages to make the place cozy and idyllic. No } \\
\text { manager is deployed to facilitate connections } \\
\text { and encounters among the coworkers. }\end{array}$ & $\begin{array}{l}\text { P600/day } \\
\text { (US\$12/day) }\end{array}$ \\
\hline Impact Hub & $\begin{array}{l}\text { Bonifacio } \\
\text { Global City }\end{array}$ & $\begin{array}{l}\text { With several branches in central business } \\
\text { districts in Metro Manila as well as an affiliation } \\
\text { with a global network, Impact Hub is perhaps the } \\
\text { most reflective of the elite coworking spaces } \\
\text { described in extant literature. Apart from bearing } \\
\text { a sleek and modern open office design, private } \\
\text { conference rooms, outdoor lounge, and an } \\
\text { exclusive kitchen/bar for coworkers, Impact Hub } \\
\text { also has community managers who facilitate } \\
\text { professional connections within the community. } \\
\text { Start-up companies and elite knowledge workers } \\
\text { make up their regular clientele as disclosed by } \\
\text { one of their community managers. }\end{array}$ & $\begin{array}{l}\text { P4,900/month } \\
\text { (US\$95) }\end{array}$ \\
\hline $\begin{array}{l}\text { First Coworking } \\
\text { Community }\end{array}$ & $\begin{array}{l}\text { Escolta, } \\
\text { Manila }\end{array}$ & $\begin{array}{l}\text { An open space for culture and knowledge } \\
\text { workers, First Coworking Community forms part } \\
\text { of the efforts of an artist collective to revive a } \\
\text { heritage district. }\end{array}$ & $\begin{array}{l}\text { P500/day } \\
\text { (US\$9.5/day) }\end{array}$ \\
\hline Diligence Café & Quezon City & $\begin{array}{l}\text { Diligence Café offers unlimited high-speed } \\
\text { internet connection, unlimited coffee, food, } \\
\text { printing service, locker rental and even shower } \\
\text { services. Reminiscent of a cozy and dimly-lit } \\
\text { café, working/studying tables are divided to } \\
\text { accommodate several workers at a time. }\end{array}$ & $\begin{array}{l}\text { P350/day } \\
\text { (US } \$ 7.5 / \text { day) }\end{array}$ \\
\hline
\end{tabular}




\begin{tabular}{|c|c|c|c|}
\hline $\begin{array}{ll}\text { The } & \text { Other } \\
\text { Room } & \end{array}$ & Quezon City & $\begin{array}{l}\text { The Other Room is a coworking space that } \\
\text { started out as a vinyl shop and is located near } \\
\text { one of the top state universities in the country. } \\
\text { Their promotional material indicates an aim to } \\
\text { cater to knowledge workers by providing them } \\
\text { with a communal and collaborative atmosphere } \\
\text { for work. }\end{array}$ & $\begin{array}{l}\text { P350/day } \\
\text { (US\$7.5/day) }\end{array}$ \\
\hline $\begin{array}{l}\text { Roots } \\
\text { Katipunan }\end{array}$ & Quezon City & $\begin{array}{l}\text { Roots Katipunan is a coworking space that also } \\
\text { features a store section for entrepreneurs, } \\
\text { students, and creatives despite its limited floor } \\
\text { space. Limited Events are frequently held in } \\
\text { Roots Katipunan but are catered to local } \\
\text { entrepreneurs and creative communities rather } \\
\text { than online freelancers. }\end{array}$ & $\begin{array}{l}\text { P350/day } \\
\text { (US } \$ 7.5 / \text { day) }\end{array}$ \\
\hline Co.Lab & Pasig City & $\begin{array}{l}\text { A coworking space that also functions as a } \\
\text { business incubator for social enterprises, Co.Lab } \\
\text { reflects the characteristics of premium } \\
\text { coworking spaces in the Global North with its } \\
\text { sleek and modern open office design. Unlike the } \\
\text { other sampled coworking spaces, Co.Lab was } \\
\text { the only one who expressed interest in tapping } \\
\text { the online gig economy freelance market. }\end{array}$ & $\begin{array}{l}\text { P6,300/month } \\
\text { (US\$115/month) }\end{array}$ \\
\hline $\begin{array}{l}\text { Cofficina Café } \\
+ \text { Cowork }\end{array}$ & $\begin{array}{l}\text { Marikina } \\
\text { City }\end{array}$ & $\begin{array}{l}\text { Located in the outskirts of a key business } \\
\text { district, Cofficina Café }+ \text { Cowork is a humble } \\
\text { coworking space that seeks to offer start-up } \\
\text { businesses, freelancers, and entrepreneurs in the } \\
\text { vicinity a space that strikes a balance between a } \\
\text { home, a café, and a working area. Bearing } \\
\text { interior design qualities evocative of hipster } \\
\text { cafés, the coworking space owner expressed } \\
\text { interest to build a community among its } \\
\text { coworkers by hosting events in collaboration } \\
\text { with students, entrepreneurs, and online } \\
\text { freelancers. }\end{array}$ & $\begin{array}{l}\text { P500/day } \\
\text { (US } \$ 9.5 / \text { day) }\end{array}$ \\
\hline
\end{tabular}


Figure 1: A visual mapping of the sampled coworking spaces in Metro Manila, Philippines.

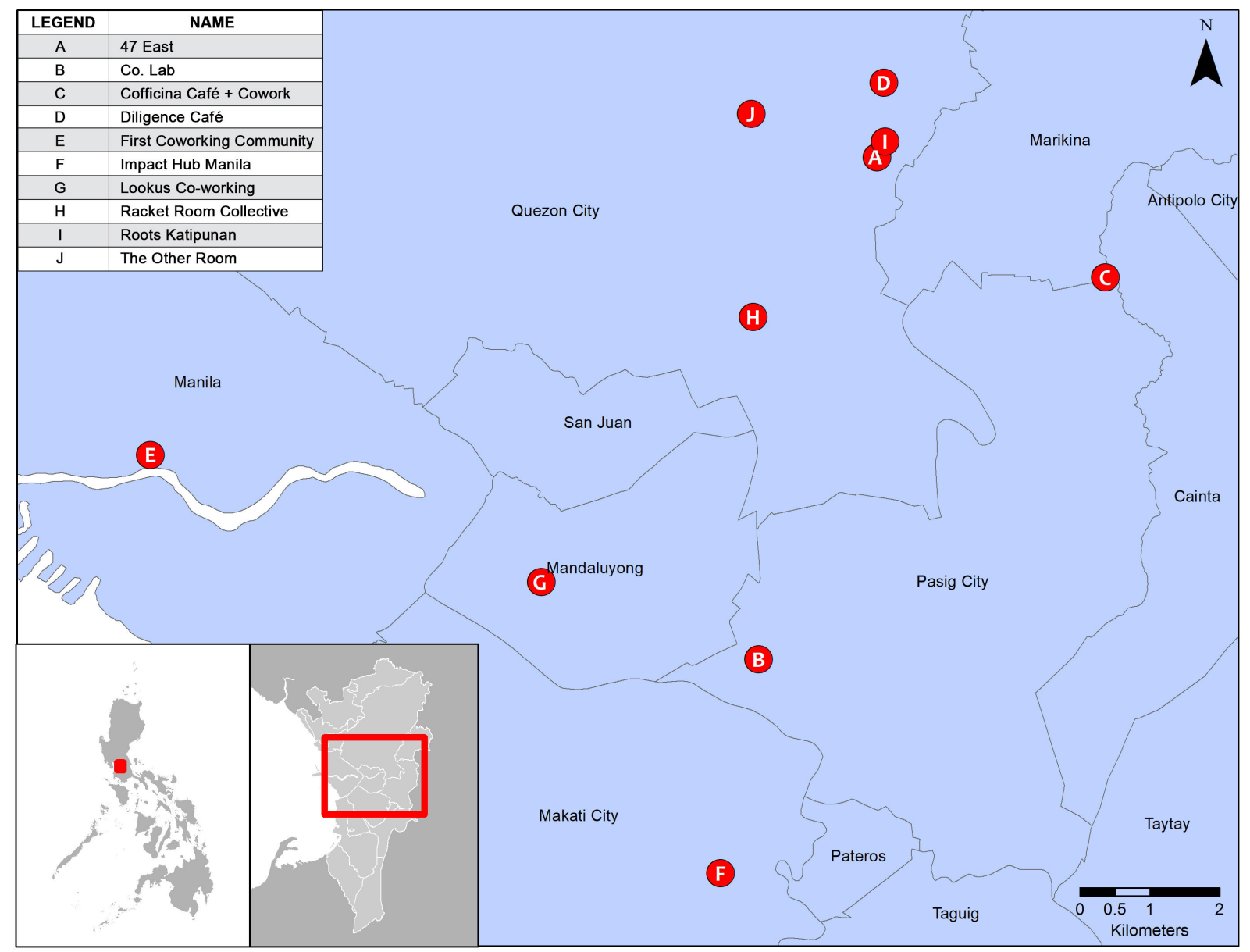

